\title{
Hasil Operasi Entropion Involusional di Rumah Sakit Dr. M. Djamil Padang
}

\author{
Hendriati, Sherly Muchlis
}

\section{Abstrak}

Entropion involusional adalah malposisi kelopak mata pada lansia. Beberapa faktor penyebab seperti kelemahan palpebra horizontal, kelemahan palpebra vertikal dengan pengurangan atau disinsersi retraktor kelopak mata bawah dan overriding otot orbicularist preseptal. Tanpa penatalaksanaan, kondisi ini bisa menyebabkan ketidaknyamanan okular, epifora dan kornea. Prosedur utamanya adalah prosedur wies dan horizontal tightening yang terdiri dari lateral tarsal strip dan horizontal shortening. Tujuan penelitian ini adalah mengevaluasi hasil rekonstruksi entropion involusional di subbagian okuloplastik bagian mata Rumah Sakit M Djamil Padang. Studi retrospektif terhadap 13 kelopak mata dari 13 pasien dengan entropion involusional antara April 2012 sampai Desember 2015. Pasien dievaluasi bulan ke 6 dan bulan 12 setelah operasi. Kami menganalisis persentase keberhasilan teknik rekonstruksi, rekurensi entropion, dan prolonged ectropionsetelah operasi. Dari 13 kelopak mata yang dioperasi, prosedur wies dilakukan pada 9 kelopak mata (69\%). Horizontal tightening yang terdiri dari prosedur wies dikombinasikan dengan teknik lateral tarsal stripdan prosedur wies + horizontal shortening dilakukan pada 3 kelopak mata (23\%) dan 1 kelopak mata (8\%). Tidak ada prosedur yang gagal. Kekambuhan entropion terjadi pada 2 pasien (15\%) yang dioperasi dengan prosedur weiss pada follow up 12 bulan. Dari 13 kelopak mata menjalani operasi entropion, tidak ada prolonged ectropion. Operasi rekonstruksi entropion involusional di Rumah Sakit M Djamil Padang memiliki tingkat keberhasilan yang tinggi dan tingkat kekambuhan yang rendah.

Kata kunci: Entropion Involusional, operasi rekonstruksi, prosedur wies, prosedur wies yang dikombinasikan dengan lateral tarsal strip, prosedur wies + horizontal shortening

\begin{abstract}
Involutional entropion is a common eyelid malposition in elderly. It has several causative factors, including horizontal lid laxity, vertical lid laxity with attenuation or disinsertion of the lower lid retractors and over riding of preseptal orbicularis muscle. Without treatment, the condition can cause ocular discomfort, epiphora and corneal ulceration. The primary procedures are wies, and horizontal tightening which consists of lateral tarsal strip and horizontal shortening. The purpose of this study is to evaluated outcome of involutional entropion surgical reconstruction in oculoplastic subdivision department of ophthalmology M Djamil Hospital Padang. A retrospective study of 13 eyelids of 13 patients with involutional entropion between April 2012-December 2015. Patients were evaluated at 6 and 12 months after surgery. We analyzed the percentage of surgical technique success, recurrence of entropion, and prolonged ectropion after surgery. Of 13 eyelids underwent surgery, wies procedure technique was performed in 9 eyelids (69\%). Horizontal tightening which consists of wies procedure combined with lateral tarsal strip technique and wies procedure + horizontal shortening were performed in 3 eyelids (23\%) and 1 eyelid (8\%). There is no failed procedures. Recurrence of entropion occurs in 2 patients (15\%) whom operated by wies procedure technique at 12 months follow up. From 13 eyelids underwent entropion surgery, there is no prolonged ectropion. Surgical reconstruction of involutional entropion in M Djamil Hospital Padang had high successful rates and low recurrence rates.
\end{abstract}

Keywords: Involutional entropion. Surgical reconstruction, Wies procedure, Wies procedure combined with lateral tarsal strip, Wies procedure + horizontal shortening

Affiliasi penulis : Bagian Mata, Fakultas Kedokteran Universitas Andalas

Korespondensi : Hendriati :irin970@yahoo.com

\section{PENDAHULUAN}

Entropion involusional merupakan suatu keadaan inversi atau berputarnya margo palpebra kearah bola mata yang dapat disertai dengan kulit palpebra karena bertambahnya usia. Entropion involusional biasanya mengenai palpebra bawah dan 94\% ditemui pada usia lebih dari 70 tahun. Kelainan ini menyebabkan iritasi permukaan bola mata sehingga menyebabkan kerusakan bola mata permanen sampai kebutaan. Keadaan yang dapat memicu timbulnya entropion involusional adalah ${ }^{1,2,3}$

1. Overridingotot protraktor palpebra inferior Otot orbikularis pretarsal merekat erat ke tarsus, sedangkan preseptal tidak melekat erat ke septum orbita sehingga pada waktu menutup mata, otot orbikularis preseptal mempunyai kecenderungan overriding ke pretarsal. Kondisi ini akan mengakibatkan pinggir bawah tarsus menjauhi bola mata dan tekanan palpebra atas ke palpebra bawah pada waktu menutup mata 
sehingga menyebabkan margo palpebra berputar ke arah bola mata.

2. Disinsersi atau kelemahanotot retraktor palpebra inferior

Ligamentum kapsulopalpebra berfungsi untuk stabilitas vertikal palpebra inferior. Apabila terjadi kelemahan ligamentum kapsulopalpebra, kondisi ini akan mengakibatkan pinggir bawah tarsus berpindah ke anterior, sehingga margo palpebra berputar ke arah bola mata.

Gambaran klinis yang menunjukkan terjadinya disinsersi retraktor adalah:

- Terdapatnya garis putih di subkonyungtiva beberapa millimeter di bawah batas tarsus inferior akibat ujung retraktor yang lepas.

- Forniks inferior lebih dalam

- Ptosis palpebra bawah

- Minimalnya pergerakan palpebra bawah saat mata melirik ke bawah.

3. Kelemahan palpebra horizontal

Tendon kantus lateral dan medial berfungsi untuk menyangga palpebra inferior. Dengan bertambahnya usia akan terjadi regangan di ligamentum kantus terutama lateral sehingga terjadi kelemahan terutama di ligamentum kantus lateral dan tarsus yang menjadi tipis dan atropi sehingga memudahkan margo palpebra inversi ke arah bola mata.

Kelemahan palpebra horizontal dapat dideteksi dengan snapback test dan distraction test. Snapback test dilakukan dengan menyuruh pasien melihat ke atas dan pemeriksa menarik palpebra pasien ke bawah. Palpebra seharusnya kembali dalam posisi anatomi normal dalam satu atau dua detik. Distraction test dilakukan dengan menarik palpebra bawah ke anterior bola mata dan mengukur jarak margo palpebra bawah dari bola mata. Palpebra normal hanya dapat ditarik 2-3 $\mathrm{mm}$ dari bola mata. Apabila palpebra bawah dapat ditarik lebih dari $6 \mathrm{~mm}$, maka terdapat kelemahan palpebra horizontal. ${ }^{1,2,3}$

Entropion involusional biasanya diatasi dengan tindakan operasi yang ditujukan untuk memperbaiki kelemahan kelopak mata yang timbul. Terdapat berbagai teknik operasi untuk mengatasi entropion kelopak mata bawah dan kelopak mata atas. Prosedur operasi biasanya dibagi atas tiga kelompok yaitu: temporizing measures,prosedur horizontal tightening, dan memperbaiki retraktor. 2,4,8

Quickert suturesyang merupakan teknik menggunakan jahitan sementara sering dipilih untuk mengatasi entropion. Akan tetapi teknik ini memiliki angka rekurensi yang cukup tinggi. 2,4,9

Wies prosedure merupakan salah satu teknik operasi yang dapat digunakan untuk memperbaiki kelopak mata atas maupun kelopak mata bawah. Prosedur blefarotomi transversal dan rotasi marginal kelopak mata tesebut dapat dilakukan dengan anestesi lokal ${ }^{2,3,9}$.

Lateral tarsal stripdan horizontal tightening(shortening) bertujuan memperbaiki kelemahan horizontal kelopak mata. Teknik ini bermanfaat untuk memperbaiki keadaan entropion terutama pada kasus entropion involusional yang disebabkan oleh kelemahan horizontal kelopak mata. $^{2,4,10}$

Kombinasi teknik operasi dapat dilakukan untuk meningkatkan angka keberhasilan dan mengurangi angka rekurensi paska tindakan rekonstruksi entropion involusional ${ }^{2,3,4}$.

\section{TUJUAN}

Untuk mengevaluasi hasil operasi rekonstruksi pasien entropion involusional pada subbagian rekonstruksi dan okuloplastik RSUP DR.M.Djamil Padang.

\section{METODE}

Penelitian ini bersifat retrospektif deskriptif terhadap pasien entropion involusional yang menjalani operasi rekonstruksi kelopak mata di RSUP Dr. M. Djamil Padang dari bulan April 2012hingga bulan Desember 2015.

Data diambil dari rekam medis dan dikelompokkan menurut diagnosa, jenis tindakan operasi rekonstruksi yang dilakukan, rekurensi serta komplikasi yang timbul paska tindakan operasi.

HASIL

Selama periode bulan April 2012 hingga bulan Desember 2015 terdapattotal 13 kasus kelopak mata terdiagnosa sebagai entropion involusional menjalani tindakan rekonstruksi kelopak mata di RSUP. Dr. M. Djamil Padang. Usia terbanyak berada pada kelompok umur antara 70 - 79 tahun yaitu 8 kasus $(61,54 \%)$. Mayoritas pasien berjenis kelamin wanita sebanyak 9 kasus $(69,23 \%)$.

Tabel 1. Distribusi menurut kelompok usia dan jenis kelamin.

\begin{tabular}{llll}
\hline \multirow{2}{*}{$\begin{array}{l}\text { Kelompok } \\
\text { usia } \\
\text { (tahun) }\end{array}$} & \multicolumn{3}{c}{ Jenis Kelamin } \\
\cline { 2 - 3 } & $\begin{array}{l}\text { Laki-laki } \\
(\%)\end{array}$ & Perempuan(\%) & \\
\hline $40-49$ & $0(0)$ & $1(7,69)$ & $1(7,69)$ \\
$50-59$ & $0(0)$ & $0(0)$ & $0(0)$ \\
$60-69$ & $0(0)$ & $2(15,38)$ & $2(15,38)$ \\
$70-79$ & $3(23,08)$ & $5(38,46)$ & $8(38,46)$ \\
$>80$ & $1(7,69)$ & $1(7,69)$ & $2(15,38)$ \\
\hline Total & $4(30,77)$ & $9(69,23)$ & $13(100)$
\end{tabular}

Selama periode bulan April 2012 hingga bulan Desember 2015, dari 13 operasi rekonstruksi kelopak mata terhadap entropion involusional di RSUP Dr. M. Djamil Padang, teknik operasi WiesProcedure merupakan tindakan yang paling banyak dilakukan yaitu terhadap 9 kasus (69,23\%). Diikuti oleh operasi kombinasi WiesProcedure disertai lateral tarsal strip pada 3 kasus $(23,08 \%)$ dan 1 kasus $(7,69 \%)$ menjalani operasi kombinasi Wies Procedure disertai horizontal shortening.

Tabel 2. Jenis Tindakan Operasi

\begin{tabular}{ll}
\hline Jenis operasi & Jumlah $\%$ \\
& (kasus)
\end{tabular}

WiesProcedure

9

Wies Procedure + lateral tarsal 3 strip 
Wies Procedure + Horizontal 1 Shortening

Total 13 100

Paska operasi tidak ditemukan kasus gagal koreksi pada semua jenis operasi. Tindakan operasi berhasil mengatasi entropion pada semua kasus (100\%).

Ditemukan 2 kasus (15,38\%) rekuren setelah setelah 12 bulan follow up.Sebelas kasus lainnya $(84,62 \%)$ tidak mengalami entropion rekuren selama follow up. Semua kasus rekuren ditemukan pada kelompok operasi menggunakan teknik Wies Prosedur.

Tabel 3. Rekurensi Entropion Paska Operasi

Jenis operasidengan rekurensi Jumlah

(kasus)

WiesProcedure

Wies Procedure + lateral tarsal

0

strip

Wies Procedure + Horizontal

0

Shortening

Total

2

\section{PEMBAHASAN}

Selama periode bulan April 2012 hingga bulan Desember 2015 terdapat 13 kasus entropion involusional menjalani koreksi dengan operasi rekonstruksi kelopak mata di RSUP DR. M. Djamil Padang. Usia terbanyak pada kelompok usia 70-79 tahun. Entropion involusional merupakan kasus yang sering ditemukan pada kelompok usia lanjut diatas usia 70 tahun. Timbulnya entropion involusional pada kelompok usia lanjut berhubungan dengan beberapa perubahan kelopak mata akibat proses penuaan.

Bertambahnya usia menyebabkan terjadinya regangan di ligamentum kantus terutama lateral sehingga terjadi kelemahan terutama di ligamentum kantus lateral dan tarsus yang menjadi tipis dan atropi sehingga memudahkan margo palpebra inversi ke arah bola mata.Overridingotot protraktor palpebra inferior, disinsersi atau kelemahanotot retraktor palpebra inferior, serta kelemahan palpebra horizontal berperan terhadap timbulnya entropion involusional.Kelemahan palpebra horizontal dapat dideteksi dengan snapback test dan distraction test. ${ }^{3,4,6}$

Ligamentum kapsulopalpebra berfungsi untuk stabilitas vertikal palpebra inferior. Apabila terjadi kelemahan ligamentum kapsulopalpebra, kondisi ini akan mengakibatkan pinggir bawah tarsus berpindah ke anterior, sehingga margo palpebra berputar ke arah bola mata. Adanya disinsersi dan kelemahan otot retraktor palpebra inferior tersebut menimbulkan ptosis palpebra bawah serta pergerakan palpebra bawah yang minimal saat mata melirik ke bawah. $3,4,10$

Pertambahan usia juga dapat menimbulkan terjadi regangan di ligamentum kantus terutama lateral sehingga terjadi kelemahan terutama di ligamentum kantus lateral dan tarsus yang menjadi tipis dan atropi sehingga memudahkan margo palpebra inversi ke arah bola mata. ${ }^{4,5}$

Jumlah total pasien operasi selama periode penelitian tercatat sebanyak 13 kasus. Pada penelitian ini didapatkan satu kasus entropion involusional pada wanita usia 48 tahun (kelompok usia 40-49 tahun). Diagnosa pada pasien ini didukung oleh hasil snap back test dan distraction test yang positif tanpa adanya riwayat trauma. Kelompok umur terbanyak pada usia 70 - 79 tahun sebanyak 8 kasus $(38,46 \%)$. Hal ini sesuai dengan rata rata kasus entropion involutional yang muncul pada usia diatas $70-\mathrm{an}^{4,5,10}$

Penelitian ini juga mendapatkan kasus terbanyak operasi entropion paling banyak pada wanita dibandingkan pria dengan perbandingan $9: 4$ kasus $(69,23 \%$ vs $30,77 \%)$. Secara umum diketahui bahwa pada entropion involusional tidak ada pengaruh jenis kelamin terhadap resiko timbulnya entropion involusional ${ }^{4,5,10}$

Selama periode penelitian tersebut sub bagian okuloplasti melakukan tiga jenis tindakan operasi terhadap kelopak mata dengan entropion involusional. tindakan Wies procedure merupakan tindakan yang paling sering dilakukan yaitu terhadap 9 kasus $(69,23 \%)$. Diikuti oleh 3 kasus $(23,08 \%)$ dengan kombinasi Wies proceduredisertai lateral tarsal strip dan 1 kasus $(7,69 \%)$ menjalani operasi kombinasi Wies Procedure disertai horizontal shortening. Tindakan Wies Procedure tanpa kombinasi dilakukan terhadap pasien dengan entropion involusional tanpa adanya tanda tanda laxity.

Tindakan Wies procedure secara tunggal maupun kombinasi dengan teknik lain diharapkan memberikan hasil yang lebih baik dan lebih permanen dengan angka keberhasilan tinggi dan rekurensi yang rendah. Dari 9 kasus yang menjalani operasi Wies procedure, dan 4 kasus dengan kombinasi didapatkan $100 \%$ kasus tidak terdapat residu entropion. Tindakan operasi yang dilakukan berhasil memperbaiki keadaan involusional yang timbul pada kelopak mata.

Paska operasi tidak ditemukan keluhan maupun komplikasi yang berarti. Keluhan yang disampaikan pasien biasanya berupa rasa kurang nyaman di daerah luka operasi terutama pada hari hari awal paska operasi. Tindakan operasi rekonstruksi yang dilakukan baik.Wiesprocedure saja maupun Wies procedure dengan kombinasi lateral tarsal strip serta Wies procedure disertai horizontal tighteningsamasama memberikan hasil yang baik sesuai dengan yang diharapkan dengan keluhan yang minimal.

Hasil yang baik ini bertahan cukup lama pada semua kelompok operasi. Follow upsetelah 12 bulan menunjukkan hasil yang berbeda pada ketiga kelompok operasi. Sebanyak 11 kasus $(84,62 \%)$ tidak menunjukkan entropion involusional pada mata yang sama setelah 12 bulan paska operasi.2 kasus $(15,38 \%)$ rekuren muncul pada kelompok dengan tindakan Wies procedure saja. Dua kasus dari total 9 kasus dengan Wies Procedure (22,22\%) mengalami entropion rekuren. Pada kelompok dengan kombinasi tindakan Wies procedure disertai lateral tarsal strip dan kelompok Wies procedure kombinasi dengan horizontal shortening tidak terdapat kasus rekuren.

Wies precedure merupakan salah satu teknik rekonstruksi kelopak untuk memperbaiki entropion. Berbagai literatur menunjukkan tindakan Wies procedure efektif untuk memperbaiki kelopak dengan entropion. Pada penelitian ini didapatkan tindakan 
Wiesprocedure berhasil dalam mengatasi entropion involusional secara baik. Meskipun hasil yang diperoleh dengan teknik Wies procedure cukup baik namun terdapat dua kasus rekuren setelah 12 bulan paska operasi.

Operasi kombinasi memberikan hasil yang berbeda, baik kombinasi Wies procedure dengan lateral tarsal strip maupun dengan horizontal shortening menunjukkan hasil yang lebih permanen tanpa rekuren selama 12 bulan followup. Penelitian ini membuktikan bahwa tindakan operasi dengan kombinasi dua teknik operasi memberikan hasil yang lebih permanen dibandingkan dengan hanya menggunakan satu teknik operasi saja.

Jang SY menemukan angka rekurensi yang tinggi $(49,3 \%)$ pada 85 pasien yang dilakukan Quickert sutures dan paling sering muncul pada perode 6 bulan setelah operasi. Penambahan prosedur lateral tarsal strip (LTS) memperbaiki faktor etiologi kelemahan palpebra bawah dan mencegah koreksi berlebihan.Sheepes MA dkk menemukan bukti yang kuat keberhasilan teknik operasi ES dikombinasi dengan LTS dalam follow up 18 bulan. Pada penelitian ini, tidak ditemukan rekurensi pada 55 pasien yang dilakukan prosedur ES dikombinasi dengan LTS.Barnes dkk menemukan angka rekurensi $2 \%$ dalam follow up 18 bulan pada 47 pasien yang dilakukan ES dikombinasi dengan LTS. ${ }^{11,12}$

\section{KESIMPULAN}

Tindakan operasi rekonstruksi pasien entropion involusional yang dilakukan di RSUP. Dr. M. Djamil Padangmenunjukkan hasil yang cukup baik tanpa komplikasi yang berarti. Tindakan Wies procedure dilakukan terhadap entropion involusional tanpa laxity yang nyata. Operasi kombinasi Wies proceduredenganlateral tarsal strip maupun kombinasi dengan horizontal shorteningdilakukan terhadap entropion involusional dengan laxity kelopak mata memberikan hasil yang baik dan bertahan lama.

\section{DAFTAR PUSTAKA}

1. Nerad JA. Diagnosis and Treatment of Entropion. Dalam: Techniques in Ophthalmic Plastic Plastic Surgery. USA: Elsevier; 2010. HIm.99-113.

2. Skorin, Jr. L. 2003. A Review of Entropion and Its Management. British Contact Lens Association 26. 2003.p.95-100

3. Crick RP. Khaw PT. Eyelids. Dalam: a Textbook of Clinical Ophthalmology: Apractical Guide to Disorders of the Eye and Their Management. Edisi ke-3. Singapore: Word Science Publishing; 2003. hlm. 447-464

4. Collin J. R. O. A Manual of Systematic Eyelid Surgery. Second Edition. Churchill Livingstone. 1989.p.7-26

5. American Academy of Ophthalmology. Periocular Malposition and Involutional Changes. In: Orbit Eyelids and Lacrimal System. Basic and Clinical Science Course. 2014-2015.San Fransisco, CA.p.189-239.

6. Brian Leatherbarrow. Upper Eyelid Entropion. in: Oculoplastic Surgery, Second edition. Informa Healthcare, London.UK. 2011.p.94-105

7. Marcus J Pfeifer. Repair of Involutional Ectropion and Entropion: Transsconjunctival surgery of the Lower Lid Retractors. In Oculoplastics and Orbit. Guthoff,R. Karowitz, JA. Springer. 2007. P 1-12.
8. Leatherbarrow B. Lower Eyelid Entropion. Dalam: Oculoplastic Surgery. Edisi ke-2. London, UK; Informa Healthcare; 2011. hlm. 75-93.

9. Kansky JJ. Eyelids: Entropion. In: Clinical Ophthalmology 6th ed. Elsevier. Philadelphia . 2011p145-146.

10. Wright M, Bell D, Scott C, and Leatherbarrow B. Everting Suture correction of lower lid Involutional entropion. British Journal of Ophthalmology. Vol 83. 1999. hlm. 1060-1063

11. Jang SY, Choi SR, Jang JW, Kim SJ, Choi HS. Long-term Surgical outcome of Quickert Sutures for Involutional Lower Eyelid Entropion. J Craniomaxillofac Surg. 2014;42(8):1629-3

12. Barnes JA, Bunce C, Olver JM. Simple Effective Surgery for Involutional Entropion Suitable for the General Ophthalmologist. The American Academy of Ophthalmology. 2006;113(1):92-6 